\title{
The Role of Surveillance in the Management of Small Renal Masses
}

\author{
Alessandro Volpe \\ Division of Urology, San Luigi Hospital, University of Turin, \\ Regione Gonzole, 10, 10043 Orbassano (Turin), Italy \\ E-mail: foxal@tin.it
}

Received December 2, 2006; Revised March 7, 2007; Accepted March 14, 2007; Published April 30, 2007

Incidentally detected, small renal masses (SRMs) have been increasing significantly in recent years due to the widespread use of improved cross-sectional imaging. A significant number of incidental SRMs are diagnosed in elderly patients who are more likely to undergo imaging for other medical issues. The natural history of SRMs has not been historically well understood because most masses are surgically removed soon after diagnosis.

Several reports of surveillance of SRMs have been published in the last few years. When followed conservatively with serial imaging, SRMs have variable growth rates with an average of $0.28 \mathrm{~cm} / y e a r$, according to a recent meta-analysis. Larger series with longer follow-up are needed, but a significant number of small tumors seem to have an indolent behavior with a slow growth rate and a limited tendency to progress. The standard of care for enhancing SRMs is surgery. Up to one-third of surgically removed, $<4-\mathrm{cm}$ tumors are histologically benign. The outcomes of current surgical treatment of histologically confirmed, <4-cm, renal cell carcinomas are excellent, but this has not led to a decrease in mortality. Based on these considerations and on the available data on the natural history of SRMs, it seems reasonable to consider that we may be overtreating these lesions. This is especially true for elderly or unfit patients who have a decreased life expectancy. In these selected patients and in patients who refuse active treatment, it seems reasonable to propose an initial period of active surveillance for incidental SRMs, with delayed intervention for those tumors that will exhibit fast growth during follow-up. Percutaneous needle biopsies of renal tumors can be safely performed with the use of modern techniques and have the potential to characterize SRMs at histologically diagnosis, thereby allowing a better selection of the conservative or active treatment that is best suited for each individual patient.

KEYWORDS: surveillance, renal mass, kidney cancer, natural history, renal cell carcinoma

Malignant tumors of the kidney cause about $2 \%$ of cancer incidence and mortality in the U.S., with an estimated 38,890 new cases and 12,840 deaths in 2006[1]. Since 1950, there has been a 126\% increase in the incidence of renal cell carcinoma (RCC) in the U.S.[2]. A raising trend has been observed worldwide and is due, in part, to the widespread use of new and improved noninvasive abdominal imaging modalities, such as ultrasonography (US), computed tomography (CT), and magnetic resonance imaging 
(MRI)[2,3,4,5,6,7,8,9,10,11,12,13]. The number of abdominal radiological exams has been increasing steadily in the last 2 decades and almost doubled between 1986 and 1994[5].

The incidence of RCC has increased in all age groups and in all clinical stages, but the greatest increase has been observed in localized tumors, which increased by 3.7\%/year from 1973 to 1998[5,6]. Most RCCs are now incidentally detected by imaging as small renal masses (SRMs) in asymptomatic patients, while in the early 1970s, the incidental detection rate was only 7 to $13 \%$ and most renal tumors were diagnosed because of symptoms, such as flank pain and hematuria[14,15,16,17,18,19,20,21,22]. Tumor size at diagnosis has also substantially decreased over time. Series from the Memorial SloanKettering Cancer Center and the Mayo Clinic report that the mean size of resected renal tumors has dropped from 7.8 to $5.3 \mathrm{~cm}$ from 1989 to 1998, and that there was a 32\% decrease in mean tumor size at the time of diagnosis, respectively[23,24].

The incidentally detected lesions are, on average, smaller and present at an earlier stage than those detected in symptomatic patients[6,10,12,13,15,18,19,24,25,26,27,28,29,30,31]. Tsui et al. reviewed the records of 633 consecutive patients who underwent surgical treatment for RCC at UCLA between 1987 and 1998. Stage I lesions were discovered in $62.1 \%$ of patients with incidental RCC and $23 \%$ with symptomatic RCC ( $p=0.001)$. Mean tumor size was $5.1 \mathrm{vs.} 7.3 \mathrm{~cm}$ in incidental vs. symptomatic cases ( $p$ $<0.05)[13]$. Patard et al. evaluated a series of 400 renal tumors and observed significantly smaller neoplasms in the incidentally detected group (5.7 vs. $8.7 \mathrm{~cm} ; p<0.001)$ [26].

A significant number of small asymptomatic tumors are benign; 32 and $33.6 \%$ of renal tumors that have been removed by laparoscopic partial nephrectomy at the Cleveland Clinic and at the Johns Hopkins Medical Institution, respectively, were found to be benign at pathology[32,33]. Frank et al. recently reviewed the pathology of 2,935 renal tumors removed at the Mayo Clinic and observed that, as tumor size decreases, there is a significant increase in the likelihood of having a benign tumor, a papillary compared to a clear cell histology, and a low-grade compared to a high-grade malignancy. In their experience, $30 \%$ of $<4-\mathrm{cm}$, surgically removed tumors were benign at pathology and over $87 \%$ of those that were clear cell RCC were low-grade tumors[34].

Finally, several authors reported that small, incidentally detected tumors are characterized by better survival outcomes[10,13,15,20,22,26,28,35,36]. The first evidence of an association between tumor size and prognosis was reported by Bell, who noted an increased rate of metastases in patients found at postmortem to have RCCs $>3 \mathrm{~cm}[37,38]$.

\section{NATURAL HISTORY OF SMALL RENAL MASSES}

Small renal neoplasms are generally removed soon after diagnosis. Therefore, their natural history has been poorly understood historically.

In the landmark report of watchful waiting of kidney tumors, Bosniak et al. retrospectively reviewed the imaging of 40 incidentally detected, $<3.5-\mathrm{cm}$, renal masses that had been followed for a mean of 3.25 years. Twenty six tumors were eventually removed after an average of 3.8 years and $84.6 \%$ of them were histologically RCCs. Variable tumor growth behaviors were observed and the overall mean linear growth rate was $0.36 \mathrm{~cm} /$ year $(0-1.1 \mathrm{~cm} /$ year). Nineteen tumors grew at lesser than $0.35 \mathrm{~cm} /$ year and no patient developed metastatic disease[39,40,41].

In the first prospective study of surveillance of renal tumors at the University Health Network of Toronto, 32 incidentally diagnosed, $<4-\mathrm{cm}$, renal masses were followed expectantly because the patients were elderly or unfit for surgery. Twenty five tumors were solid and seven complex cystic (four Bosniak III and three Bosniak IV). The patients were prospectively followed with serial abdominal imaging for a mean of 27.9 months (5.3-143) and each mass had at least three follow-up measurements. Tumor volume, in addition to single and bidimensional diameters, was calculated from each follow-up image or report. Nine masses in eight patients were surgically removed after an average of 38 months of follow-up because of the surgeon's concern or the patient's anxiety that the tumor was enlarging. All tumors were clear cell RCCs, except one that was an oncocytoma. The overall average growth rate, considered the 
cube root of the volume, was $0.1 \mathrm{~cm} /$ year and was not associated with either initial size $(p=0.28)$ or mass type ( $p=0.41)$ (Fig. 1). Seven masses (22\%) reached $4 \mathrm{~cm}$ in diameter after 12-85 months of follow-up. Eight (25\%) doubled their volumes within 12 months. Overall, eleven (34\%) fulfilled one of these two criteria of rapid growth. No patient progressed to metastatic disease, while two patients died of unrelated causes[42].

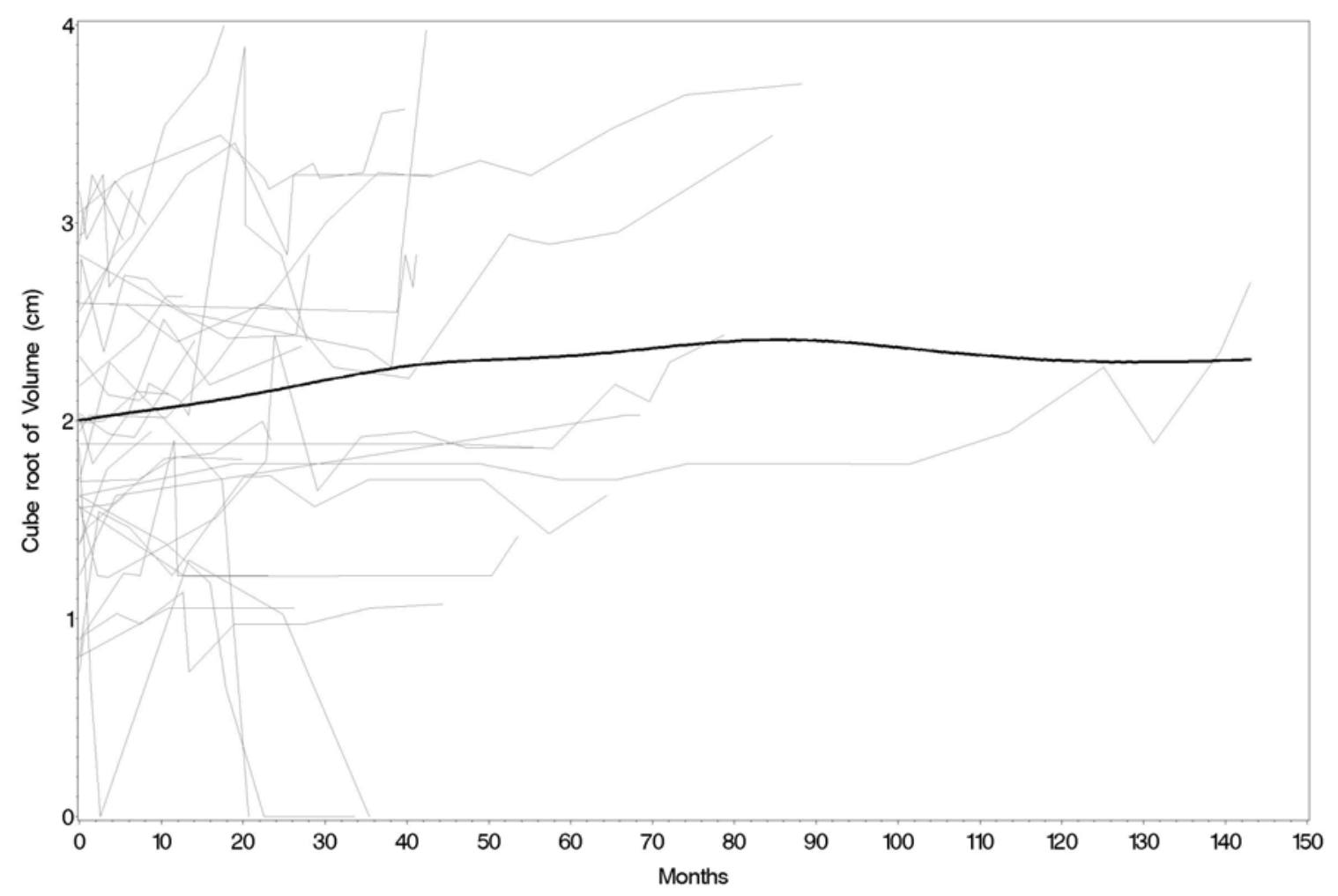

FIGURE 1. Individual observed patterns of tumor growth rate over time of 32 SRMs managed by active surveillance. A summary curve indicating the average growth rate is superimposed. (From Volpe et al.[42], with permission.)

A similar experience has been reported by Kassouf et al., who serially imaged 24 patients with SRMs. Most of the tumors did not demonstrate significant growth during the surveillance period. The mean growth rate of the five fast-growing tumors was $0.49 \mathrm{~cm} /$ year or $7.3 \mathrm{cc} /$ year. The four tumors that were removed during the follow-up were all histologically RCC (three clear cell and one papillary type). No metastasis was documented[43].

Other experiences of watchful waiting of SRMs have been published in the last few years with similar results[44,45,46] (see Table 1). Chawla et al. recently carried out a meta-analysis of the available studies on this topic; 234 renal masses from eight different series, with a mean size at presentation of $2.6 \mathrm{~cm}$, were included in the analysis. With a mean follow-up of 34 months, mean tumor growth rate was $0.28 \mathrm{~cm}$ yearly. Pathological confirmation was available in $46 \%$ of the cases and $92 \%$ of the masses were confirmed as RCC variants. Lesion size at presentation did not predict the overall growth rate $(p=$ 0.46)[47].

Interestingly, Lamb et al. observed a slow growth rate also in larger renal tumors. They followed a series of 36 renal masses with an average size of $7.2 \mathrm{~cm}$ at diagnosis, in patients who were considered unsuitable for surgery or were unwilling to have surgery. Two-thirds of the masses were biopsied and the 
diagnosis of RCC was confirmed in all cases except one. The authors observed a growth rate of 0.0-1.76 $\mathrm{cm} /$ year, with $55 \%$ of patients showing no increase in tumor size[48].

At present, progression to metastatic disease has been described for only three renal neoplasms managed by surveillance. However, the first tumor was already $>8 \mathrm{~cm}$ in diameter at diagnosis, the second metastasized after growing to $>8 \mathrm{~cm}$ during follow-up, and the third spread after more than 10 years of observation[46,47,48].

TABLE 1

Outcomes of Studies of Active Surveillance for SRMs

\begin{tabular}{lcccccc}
\hline & $\begin{array}{c}\text { Number } \\
\text { of } \\
\text { Masses }\end{array}$ & $\begin{array}{c}\text { Average } \\
\text { Tumor } \\
\text { Sze (cm) }\end{array}$ & $\begin{array}{c}\text { Average } \\
\text { Follow- } \\
\text { Up } \\
\text { (months) }\end{array}$ & $\begin{array}{c}\text { Average } \\
\text { Tumor } \\
\text { Growth } \\
\text { (cm/year) }\end{array}$ & $\begin{array}{c}\text { Masses } \\
\text { Eventually } \\
\text { Surgically } \\
\text { Removed (\%) }\end{array}$ & $\begin{array}{c}\text { Histologically } \\
\text { Confirmed } \\
\text { RCC (\%) }\end{array}$ \\
\hline Bosniak et al.[40] & 40 & 1.73 & 39 & 0.36 & $26(65 \%)$ & $22 / 26(85 \%)$ \\
Volpe et al.[42] & 32 & 2.48 & 27.9 & 0.1 & $9(28 \%)$ & $8 / 9(89 \%)$ \\
Kassouf et al.[43] & 24 & 3.27 & 31.6 & 0.09 & $4(17 \%)$ & $4 / 4(100 \%)$ \\
Kato et al.[44] & 18 & 1.98 & 22.5 & 0.42 & $18(100 \%)$ & $18 / 18(100 \%)$ \\
Wehle et al.[45] & 29 & 1.83 & 32 & 0.12 & $4(14 \%)$ & $3 / 4(75 \%)$ \\
Sowery and Siemens[46] & 22 & 4.08 & 26 & 0.86 & $2(9 \%)$ & $2 / 2(100 \%)$ \\
Chawla et al.[47] & 61 & 2.97 & 36 & 0.20 & $21(34 \%)$ & $17 / 21(81 \%)$ \\
\hline
\end{tabular}

One of the limitations in interpreting these studies is the lack of pathological data on the tumors that remain on surveillance. However, since the vast majority of tumors that have been removed after a period of watchful waiting were histologically RCC and the same radiographic criteria were used to assess all masses, a large proportion of the remaining lesions should also be histologically malignant.

The studies on active surveillance that have been published to date are mostly retrospective, have a relatively short follow-up, and include a limited number of patients. However, their results are consistent and clearly suggest that a large number of incidentally detected SRMs have a slow growth rate and an indolent clinical behavior if managed conservatively.

\section{ACTIVE SURVEILLANCE OF SMALL RENAL MASSES}

The standard of care for small, localized, renal neoplasms is either radical or partial nephrectomy. Nephron-sparing surgery, originally proposed for patients with a solitary kidney, impaired renal function, or bilateral tumors, is becoming the gold standard for smaller RCCs, given its comparable cancer control rate and reduced impact on renal function. Laparoscopic partial nephrectomy is a challenging technique, but it is already preferred to open partial nephrectomy in centers with advanced laparoscopic expertise.

The current management of SRMs yields excellent results. In the Mayo Clinic experience with surgical treatment of RCC, the 5-year cancer-specific survival for pT1a tumors is 97\%[49]. In an international, multicenter study of 1,454 patients, Patard et al. reported a 5-year cancer-specific survival approaching 97\% for pT1a tumors after nephron-sparing surgery[50]. In the Cleveland Clinic experience with laparoscopic partial nephrectomy, cancer-specific survival was $100 \%$ at a median follow-up of 42 months, with no local or port-site recurrence[32].

Morbidity from nephrectomy has decreased with improved techniques, but it is still significant and is reported to occur in 11 to $40 \%$ of cases in recent series[24,51,52,53,54]. Furthermore, most incidental tumors are detected in the elderly, who are more likely to undergo radiological examinations for other 
medical issues. These patients frequently have significant comorbidities and have a higher risk of perioperative mortality and morbidity.

Despite the significant increase in the diagnosis of localized neoplasms and the excellent outcomes of surgical treatment of SRMs, mortality of RCC has not decreased in the last few years and, in fact, it is slowly increasing. This probably implies that many small, incidental renal tumors have a long natural history and limited capacity to progress, while most RCCs that actually lead to death still present with symptomatic, locally advanced, or metastatic disease. This argument is supported by autopsy reports that shows that 67 to $74 \%$ of RCCs remained undetected until death before the widespread use of imaging and only 8.9 to $20 \%$ of undiagnosed RCCs were eventually responsible for the patient's death[3,55,56]

Based on these observations and on the analysis of the emerging data on the natural history of SRMs, it appears we may be overtreating these lesions and the current practice of immediate surgery for all newly diagnosed small renal tumors may have to be re-examined. In fact, it seems that a significant number of small, incidentally discovered, renal neoplasms are not histologically malignant or have an indolent clinical behavior. Therefore, they may not be an immediate threat to the patient's life. The risks of surgical treatment are only acceptable if the patient's life expectancy is longer than the time the tumor will take to progress. A recent study reviewed a series of 2,570 radical nephrectomies and indicated that approximately 5,10 , and $20 \%$ of patients who undergo surgery for RCC succumb to other cause mortality at 1, 10, and 20 years of follow-up[57]. In the Cleveland Clinic experience, $14 \%$ of patients died of other causes with a mean follow-up of 42 months[32].

A period of initial observation with delayed surgical treatment reserved for those tumors that exhibit a fast growth during follow-up, i.e., those that have rapid doubling times or whose volumes or bidimensional diameters reach a threshold we consider to be at risk for progression, may be appropriate in patients who are elderly or infirm. This is the concept of active surveillance. An upper limit of 3-4 cm in diameter and a volume doubling time $>1$ year are commonly used to identify renal masses that are at low risk of developing metastases and have a better survival rate[37,38,40,42,58,59,60,61]. We need further experience to propose definitive thresholds for treatment, but these appear to be reasonable limits for size and growth rate until which surveillance might be considered before suggesting therapeutic intervention in selected patients. There are reports that judicious delayed surgery does not appear to adversely impact clinical and pathological outcomes, even if the tumors are high grade[62,63]. However, large multicenter studies with long follow-up are needed to confirm the safety of active surveillance. At the present time, in the absence of effective treatment for metastatic disease, this strategy should not be recommended for young and fit patients.

The optimal follow-up schedule for patients in active surveillance has not been defined. At the University Health Network in Toronto, a triphasic, abdominal CT scan is performed at 3-month intervals for 1 year, then every 6 months to 3 years, and yearly thereafter if there is minimal or no growth. Monitoring SRMs is labor intensive and requires good patient compliance and careful organization.

The risk of measurement error at imaging is a concern in the conservative management of patients with small renal tumors. However, several authors reported reproducible and accurate tumor volume measurements by the use of CT scan and MRI[64,65,66,67]. A higher degree of inter- and intraobserver variability in measurements seems to occur with the use of US[68,69]. Masses with cystic components represent a special problem because tumor growth rate can be easily either overestimated or underestimated if the volume of cystic fluid grows at a different rate than the tumor cell volume.

Percutaneous needle biopsy is technically feasible today in an outpatient setting and can provide useful material for diagnosis in over $90 \%$ of cases in centers with expertise[70,71,72]. With the use of modern techniques, the risk of significant bleeding or needle track implantation is extremely rare. Significant grade heterogeneity is not very common in small tumors so that biopsies are likely to provide tissue that is representative of the entire tumor in the majority of cases. The histological characterization of SRMs with percutaneous biopsies has the potential to allow a better selection of patients for active surveillance. In fact, biopsies can identify the few small and high-grade tumors that should not be followed conservatively, but removed surgically up front. Also, a benign biopsy can dictate a lessintensive follow-up schedule, especially in elderly and frail patients. 
A future goal is to go beyond classical histology and to identify genetic and molecular markers (members of the hypoxia-inducible/angiogenesis pathway, proliferation/apoptosis markers, adhesion molecules, etc.) that can reliably predict the clinical behavior of RCCs at needle biopsy. The highthroughput gene microarrays technology has the potential to provide significant prognostic information. In fact, there is increasing evidence that gene expression profiles can reveal histological subtypes and clinical outcomes of RCC[73]. Good-quality microarrays can be obtained with the amplification of the RNA from the small amount of tissue from needle biopsies.

In summary, the measurement of tumor growth rate seems to be helpful for initial conservative management of patients with incidentally diagnosed, small renal tumors. With a judicious use of delayed intervention for tumors with a fast growth rate, the risk of progression to metastatic disease appears to be little. However, longer follow-up is needed to confirm these observations. At the present time, active surveillance of SRMs should be considered only for elderly patients, patients with significant comorbidity, and patients who refuse active treatment. Needle biopsies can play a significant role in selecting those patients that are better candidates for this approach. Finally, the discovery of reliable genetic and molecular prognostic markers are needed in order to better differentiate small renal tumors with different aggressiveness and metastatic potential, thereby enabling the urologist to choose the most suitable conservative or active treatment for each patient.

\section{ACKNOWLEDGMENTS:}

This review originates from the clinical and scientific experience with active surveillance of SRMs I developed during a 2-year urologic oncology fellowship at the University of Toronto, Ontario, Canada. A special acknowledgment goes to Dr. Michael A.S. Jewett, who has been an outstanding surgical and scientific teacher, and led me in the clinical research in this field.

\section{REFERENCES}

1. Jemal, A., Siegel, R., Ward, E., Murray, T., Xu, J., Smigal, C., and Thun, M.J. (2006) Cancer statistics, 2006. CA Cancer J. Clin. 56, 106-130.

2. Pantuck, A.J., Zisman, A., and Belldegrun, A.S. (2001) The changing natural history of renal cell carcinoma. J. Urol. 166, 1611-1623.

3. Wunderlich, H., Schumann, S., Jantitzky, V., Moravek, P., Podhola, M., Kosmehl, H., and Schubert, J. (1998) Increase of renal cell carcinoma incidence in central Europe. Eur. Urol. 33, 538-541.

4. Rofsky, N.M. and Bosniak, M.A. (1997) MR imaging in the evaluation of small $(<$ or $=3.0 \mathrm{~cm})$ renal masses. Magn. Reson. Imaging Clin. N. Am. 5, 67-81.

5. Chow, W.H., Devesa, S.S., Warren, J.L., and Fraumeni, J.F., Jr. (1999) Rising incidence of renal cell cancer in the United States. JAMA 281, 1628-1631.

6. Hock, L.M., Lynch, J., and Balaji, K.C. (2002) Increasing incidence of all stages of kidney cancer in the last 2 decades in the United States: an analysis of surveillance, epidemiology and end results program data. J. Urol. 167, 57-60.

7. Mathew, A., Devesa, S.S., Fraumeni, J.F., Jr., and Chow, W.H. (2002) Global increases in kidney cancer incidence, 1973-1992. Eur. J. Cancer Prev. 11, 171-178.

8. Lightfoot, N., Conlon, M., Kreiger, N., Bissett, R., Desai, M., Warde, P., and Prichard, H.M. (2000) Impact of noninvasive imaging on increased incidental detection of renal cell carcinoma. Eur. Urol. 37, 521-527.

9. $\quad$ Liu, S., Semenciw, R., Morrison, H., Schanzer, D., and Mao, Y. (1997) Kidney cancer in Canada: the rapidly increasing incidence of adenocarcinoma in adults and seniors. Can. J. Public Health 88, 99-104.

10. Siemer, S., Uder, M., Humke, U., Lindenmeier, T., Moll, V., Rudenauer, E., Maurer, J., and Ziegler, M. (2000) [Value of ultrasound in early diagnosis of renal cell carcinoma]. Urologe A 39, 149-153.

11. Wills, J.S. (1997) The diagnosis and management of small $(<$ or $=3 \mathrm{~cm})$ renal neoplasms: a commentary. Semin. Ultrasound CT MR 18, 75-81.

12. Porena, M., Vespasiani, G., Rosi, P., Costantini, E., Virgili, G., Mearini, E., and Micali, F. (1992) Incidentally detected renal cell carcinoma: role of ultrasonography. J. Clin. Ultrasound 20, 395-400.

13. Tsui, K.H., Shvarts, O., Smith, R.B., Figlin, R., de Kernion, J.B., and Belldegrun, A. (2000) Renal cell carcinoma: prognostic significance of incidentally detected tumors. J. Urol. 163, 426-430. 
14. Skinner, D.G., Colvin, R.B., Vermillion, C.D., Pfister, R.C., and Leadbetter, W.F. (1971) Diagnosis and management of renal cell carcinoma. A clinical and pathologic study of 309 cases. Cancer 28, 1165-1177.

15.

16.

17.

18.

19.

20.

21.

22.

Konnak, J.W. and Grossman, H.B. (1985) Renal cell carcinoma as an incidental finding. J. Urol. 134, 1094-1096.

Shintaku, I., Suzuki, Y., Uchi, K., Morita, M., and Terasawa, Y. (2000) [Characteristics of incidentally detected renal cell carcinoma by ultrasonography at health check-up]. Nippon Hinyokika Gakkai Zasshi 91, 43-48.

Russo, P. (2001) Localized renal cell carcinoma. Curr. Treat. Options Oncol. 2, 447-455.

Luciani, L.G., Cestari, R., and Tallarigo, C. (2000) Incidental renal cell carcinoma-age and stage characterization and clinical implications: study of 1092 patients (1982-1997). Urology 56, 58-62.

Homma, Y., Kawabe, K., Kitamura, T., Nishimura, Y., Shinohara, M., Kondo, Y., Saito, I., Minowada, S., and Asakage, Y. (1995) Increased incidental detection and reduced mortality in renal cancer--recent retrospective analysis at eight institutions. Int. J. Urol. 2, 77-80.

Bos, S.D., Mellema, C.T., and Mensink, H.J. (2000) Increase in incidental renal cell carcinoma in the northern part of the Netherlands. Eur. Urol. 37, 267-270.

Jayson, M. and Sanders, H. (1998) Increased incidence of serendipitously discovered renal cell carcinoma. Urology 51, 203-205.

Bretheau, D., Lechevallier, E., Eghazarian, C., Grisoni, V., and Coulange, C. (1995) Prognostic significance of incidental renal cell carcinoma. Eur. Urol. 27, 319-323.

Lau, W.K., Blute, M.L., Weaver, A.L., Torres, V.E., and Zincke, H. (2000) Matched comparison of radical nephrectomy vs elective nephron-sparing surgery in patients with unilateral renal cell carcinoma and a normal contralateral kidney. Mayo Clin. Proc. 75, 1236.

Lee, C.T., Katz, J., Shi, W., Thaler, H.T., Reuter, V.E., and Russo, P. (2000) Surgical management of renal tumors $4 \mathrm{~cm}$. or less in a contemporary cohort. J. Urol. 163, 730-736.

Licht, M.R., Novick, A.C., and Goormastic, M. (1994) Nephron sparing surgery in incidental versus suspected renal cell carcinoma. J. Urol. 152, 39-42.

Patard, J.J., Rodriguez, A., Rioux-Leclercq, N., Guille, F., and Lobel, B. (2002) Prognostic significance of the mode of detection in renal tumours. BJU Int. 90, 358-363.

Russo, P. (2000) Renal cell carcinoma: presentation, staging, and surgical treatment. Semin. Oncol. 27, 160-176.

Thompson, I.M. and Peek, M. (1988) Improvement in survival of patients with renal cell carcinoma--the role of the serendipitously detected tumor. J. Urol. 140, 487-490.

Marshall, F.F., Stewart, A.K., and Menck, H.R. (1997) The National Cancer Data Base: report on kidney cancers. The American College of Surgeons Commission on Cancer and the American Cancer Society. Cancer 80, 2167-2174.

Aso, Y. and Homma, Y. (1992) A survey on incidental renal cell carcinoma in Japan. J. Urol. 147, 340-343.

Katz, D.L., Zheng, T., Holford, T.R., and Flannery, J. (1994) Time trends in the incidence of renal carcinoma: analysis of Connecticut Tumor Registry data, 1935-1989. Int. J. Cancer 58, 57-63.

Moinzadeh, A., Gill, I.S., Finelli, A., Kaouk, J., and Desai, M. (2006) Laparoscopic partial nephrectomy: 3-year followup. J. Urol. 175, 459-462.

Link, R.E., Bhayani, S.B., Allaf, M.E., Varkarakis, I., Inagaki, T., Rogers, C., Su, L.M., Jarrett, T.W., and Kavoussi, L.R. (2005) Exploring the learning curve, pathological outcomes and perioperative morbidity of laparoscopic partial nephrectomy performed for renal mass. J. Urol. 173, 1690-1694.

Frank, I., Blute, M.L., Cheville, J.C., Lohse, C.M., Weaver, A.L., and Zincke, H. (2003) Solid renal tumors: an analysis of pathological features related to tumor size. J. Urol. 170, 2217-2220.

Kessler, O., Mukamel, E., Hadar, H., Gillon, G., Konechezky, M., and Servadio, C. (1994) Effect of improved diagnosis of renal cell carcinoma on the course of the disease. J. Surg. Oncol. 57, 201-204.

Sweeney, J.P., Thornhill, J.A., Graiger, R., McDermott, T.E., and Butler, M.R. (1996) Incidentally detected renal cell carcinoma: pathological features, survival trends and implications for treatment. Br. J. Urol. 78, 351-353.

Bell, E.T. (1938) A classification of renal tumors with observations on the frequency of the various types. J. Urol. 39, 238.

Bell, E.T. (1950) Renal Disease. Lea and Febiger, Philadelphia.

Bosniak, M.A. (1995) Observation of small incidentally detected renal masses. Semin. Urol. Oncol. 13, 267-272.

Bosniak, M.A., Birnbaum, B.A., Krinsky, G.A., and Waisman, J. (1995) Small renal parenchymal neoplasms: further observations on growth. Radiology 197, 589-597.

Bosniak, M.A., Krinsky, G.A., and Waisman, J. (1996) Management of small incidental renal parenchymal tumors by watchful-waiting in selected patients based on observations of tumor growth rates. J. Urol. 155, suppl., 584A, abstract 1092.

Volpe, A., Panzarella, T., Rendon, R.A., Haider, M.A., Kondylis, F.I., and Jewett, M.A. (2004) The natural history of incidentally detected small renal masses. Cancer 100, 738-745.

Kassouf, W., Aprikian, A.G., Laplante, M., and Tanguay, S. (2004) Natural history of renal masses followed expectantly. J. Urol. 171, 111-113; discussion 113.

Kato, M., Suzuki, T., Suzuki, Y., Terasawa, Y., Sasano, H., and Arai, Y. (2004) Natural history of small renal cell carcinoma: evaluation of growth rate, histological grade, cell proliferation and apoptosis. J. Urol. 172, 863-866. 
45. Wehle, M.J., Thiel, D.D., Petrou, S.P., Young, P.R., Frank, I., and Karsteadt, N. (2004) Conservative management of incidental contrast-enhancing renal masses as safe alternative to invasive therapy. Urology 64, 49-52.

46. Sowery, R.D. and Siemens, D.R. (2004) Growth characteristics of renal cortical tumors in patients managed by watchful waiting. Can. J. Urol. 11, 2407-2410.

47. Chawla, S.N., Crispen, P.L., Hanlon, A.L., Greenberg, R.E., Chen, D.Y., and Uzzo, R.G. (2006) The natural history of observed enhancing renal masses: meta-analysis and review of the world literature. J. Urol. 175, 425-431.

48. Lamb, G.W., Bromwich, E.J., Vasey, P., and Aitchison, M. (2004) Management of renal masses in patients medically unsuitable for nephrectomy--natural history, complications, and outcome. Urology 64, 909-913. Frank, I., Blute, M.L., Leibovich, B.C., Cheville, J.C., Lohse, C.M., and Zincke, H. (2005) Independent validation of the 2002 American Joint Committee on cancer primary tumor classification for renal cell carcinoma using a large, single institution cohort. J. Urol. 173, 1889-1892.

50. Patard, J.J., Shvarts, O., Lam, J.S., Pantuck, A.J., Kim, H.L., Ficarra, V., Cindolo, L., Han, K.R., De La Taille, A., Tostain, J., Artibani, W., Abbou, C.C., Lobel, B., Chopin, D.K., Figlin, R.A., Mulders, P.F., and Belldegrun, A.S. (2004) Safety and efficacy of partial nephrectomy for all T1 tumors based on an international multicenter experience. J. Urol. 171, 2181-2185, quiz 2435.

51. Mejean, A., Vogt, B., Quazza, J.E., Chretien, Y., and Dufour, B. (1999) Mortality and morbidity after nephrectomy for renal cell carcinoma using a transperitoneal anterior subcostal incision. Eur. Urol. 36, 298-302.

52. Fontaine, E. and Chretien, Y. (2001) [Systematic conservative surgery for kidney cancer smaller than $4 \mathrm{~cm}$ : multicenter study]. Prog. Urol. 11, 621-624. Uzzo, R.G. and Novick, A.C. (2001) Nephron sparing surgery for renal tumors: indications, techniques and outcomes. $J$. Urol. 166, 6-18.

54. Stephenson, A.J., Hakimi, A.A., Snyder, M.E., and Russo, P. (2004) Complications of radical and partial nephrectomy in a large contemporary cohort. J. Urol. 171, 130-134.

55. Hajdu, S.I., Berg, J.W., and Foote, F.W., Jr. (1970) Clinically unrecognized, silent renal-cell carcinoma in elderly cancer patients. J. Am. Geriatr. Soc. 18, 443-449. pathological aspects. Eur. Urol. 18(Suppl 2), 2-3.

57. $\quad$ Karakiewicz, P.I., Lewinshtein, D., Perrotte, P., Briganti, A., Felix Chun, K.H., Guille, F., Lobel, B., Patard, J.J., Ficarra, V., Artibani, W., Cindolo, L., Tostain, J., Abbou, C.C., Chopin, D.K., and De La Taille, A. (2006) The effect of competing mortality on the risk of cancer-specific survival in kidney cancer. J. Urol. 175, 240, Abstract 739.

58. Frank, I., Blute, M.L., Cheville, J.C., Lohse, C.M., Weaver, A.L., and Zincke, H. (2002) An outcome prediction model for patients with clear cell renal cell carcinoma treated with radical nephrectomy based on tumor stage, size, grade and necrosis: the SSIGN score. J. Urol. 168, 2395-2400.

59. Zisman, A., Pantuck, A.J., Chao, D., Dorey, F., Said, J.W., Gitlitz, B.J., de Kernion, J.B., Figlin, R.A., and Belldegrun, A.S. (2001) Reevaluation of the 1997 TNM classification for renal cell carcinoma: T1 and T2 cutoff point at 4.5 rather than $7 \mathrm{~cm}$. better correlates with clinical outcome. J. Urol. 166, 54-58.

60. Walther, M.M., Choyke, P.L., Glenn, G., Lyne, J.C., Rayford, W., Venzon, D., and Linehan, W.M. (1999) Renal cancer in families with hereditary renal cancer: prospective analysis of a tumor size threshold for renal parenchymal sparing surgery. J. Urol. 161, 1475-1479.

61. Bosniak, M.A. (1991) The small (less than or equal to $3.0 \mathrm{~cm}$ ) renal parenchymal tumor: detection, diagnosis, and controversies. Radiology 179, 307-317.

62. Viterbo, R., Crispen, P.L., Greenberg, R.E., Chen, D.Y.T., and Uzzo, R.G. (2006) Delayed management of high grade renal tumors. J. Urol. 175, 350, Abstract 1089.

63. McRackan, D., Kouba, E., Wallen, E.M., and Pruthi, R.S. (2006) Expectant management of small renal masses: does a delay in therapy pose a clinical or pathological risk to the patient? J. Urol. 175, 237, Abstract 732.

64. Wheatley, J.M., Rosenfield, N.S., Heller, G., Feldstein, D., and LaQuaglia, M.P. (1995) Validation of a technique of computer-aided tumor volume determination. J. Surg. Res. 59, 621-626.

65. Tann, M., Sopov, V., Croitoru, S., Nativ, O., Moskovitz, B., Bar-Meir, E., and Groshar, D. (2001) How accurate is helical CT volumetric assessment in renal tumors? Eur. Radiol. 11, 1435-1438.

66. Nawaratne, S., Fabiny, R., Brien, J.E., Zalcberg, J., Cosolo, W., Whan, A., and Morgan, D.J. (1997) Accuracy of volume measurement using helical CT. J. Comput. Assist. Tomogr. 21, 481-486.

67. Coulam, C.H., Bouley, D.M., and Sommer, F.G. (2002) Measurement of renal volumes with contrast-enhanced MRI. J. Magn. Reson. Imaging 15, 174-179.

68. Schlesinger, A.E., Hernandez, R.J., Zerin, J.M., Marks, T.I., and Kelsch, R.C. (1991) Interobserver and intraobserver variations in sonographic renal length measurements in children. AJR Am. J. Roentgenol. 156, 1029-1032.

69. Hederstrom, E. and Forsberg, L. (1985) Accuracy of ultrasonography compared with urography in detection of intrarenal dilatation in children. Acta Radiol. Diagn. (Stockh.) 26, 201-207.

70. Neuzillet, Y., Lechevallier, E., Andre, M., Daniel, L., and Coulange, C. (2004) Accuracy and clinical role of fine needle percutaneous biopsy with computerized tomography guidance of small (less than $4.0 \mathrm{~cm}$ ) renal masses. J. Urol. 171, 1802-1805.

71. Wood, B.J., Khan, M.A., McGovern, F., Harisinghani, M., Hahn, P.F., and Mueller, P.R. (1999) Imaging guided biopsy 
of renal masses: indications, accuracy and impact on clinical management. J. Urol. 161, 1470-1474.

72. Caoili, E.M., Bude, R.O., Higgins, E.J., Hoff, D.L., and Nghiem, H.V. (2002) Evaluation of sonographically guided percutaneous core biopsy of renal masses. AJR Am. J. Roentgenol. 179, 373-378.

73. Takahashi, M., Rhodes, D.R., Furge, K.A., Kanayama, H., Kagawa, S., Haab, B.B., and Teh, B.T. (2001) Gene expression profiling of clear cell renal cell carcinoma: gene identification and prognostic classification. Proc. Natl. Acad. Sci. U. S. A. 98, 9754-9759.

\section{This article should be cited as follows:}

Volpe, A. (2007) The role of surveillance in the management of small renal masses. TSW Urology 2, 134-142. DOI 10.1100/tswurol.2007.103. 


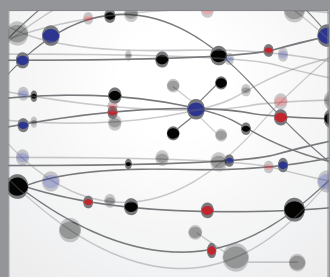

The Scientific World Journal
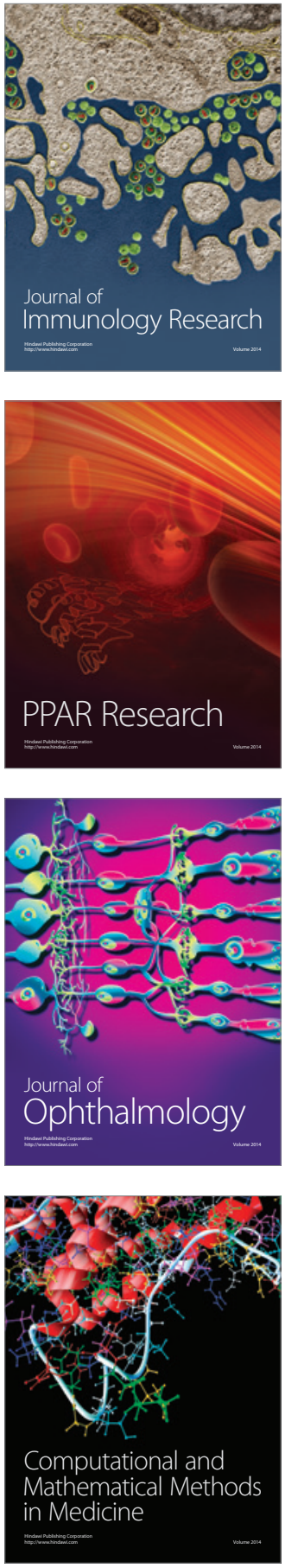

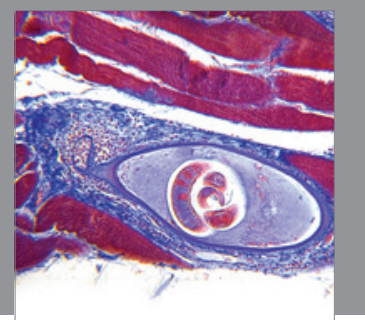

Gastroenterology

Research and Practice
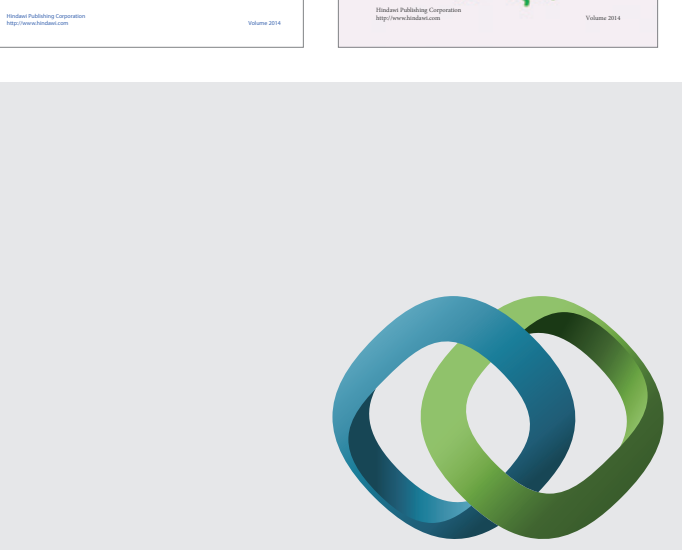

\section{Hindawi}

Submit your manuscripts at

http://www.hindawi.com
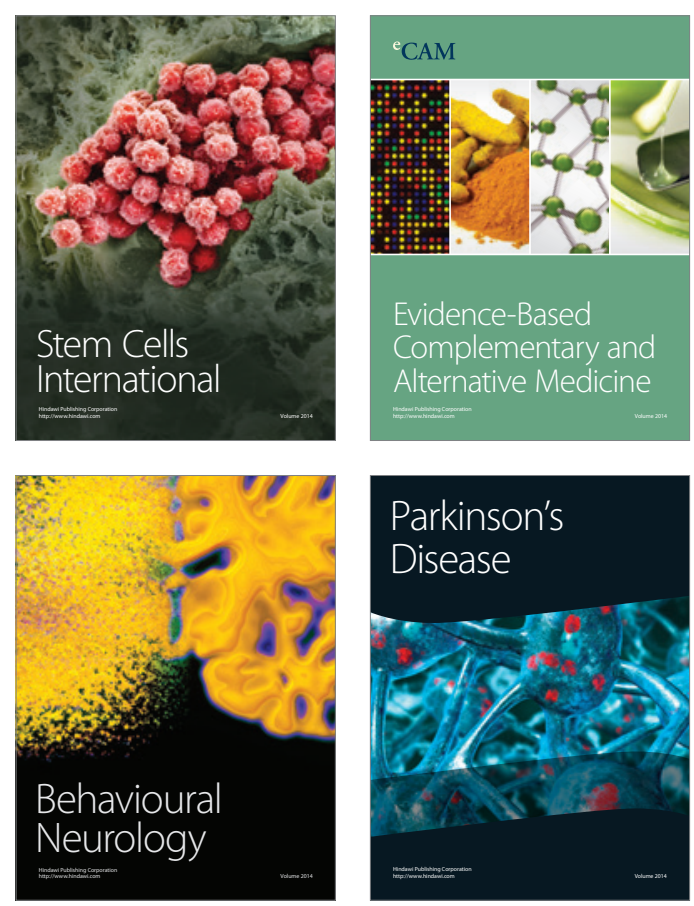

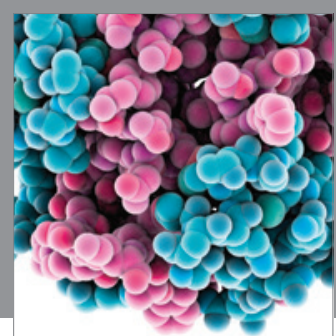

Journal of
Diabetes Research

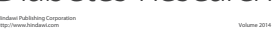

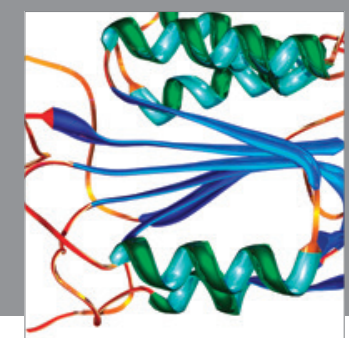

Disease Markers
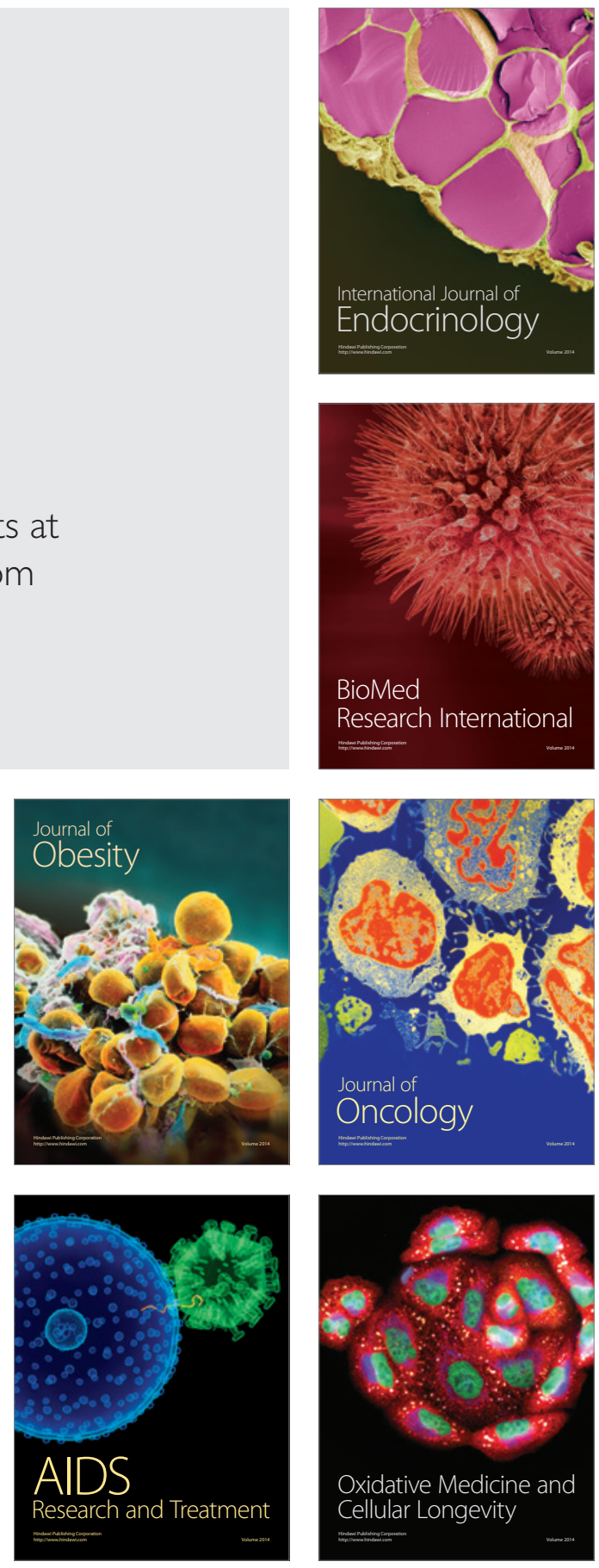